\title{
Kinesitherapeutic behaviour in conservative treatment of coxarthrosis - case report
}

\author{
Maria Becheva ${ }^{1}$, Gergana Petrova ${ }^{1}$, Angelina Kirkova², Petar Atanasov ${ }^{3}$ \\ 1 Department of Nursing, Faculty of Public Health, Medical University - Plovdiv, Plovdiv 4002,15A Vasil Aprilov Blvd, Bulgaria \\ 2 Department of Medical Informatics, Biostatistics and E-learning, Faculty of Public Health, Medical University - Plovdiv, Plovdiv 4002, 15A Vasil \\ Aprilov Blvd., Bulgaria \\ 3 Clinic of Internal Diseases, UMHATEM "N. I. Pirogov" - Sofia, Bulgaria \\ Corresponding author: Maria Becheva (olivier@abv.bg)
}

Received 13 May 2019 • Accepted 10 June 2019 • Published 23 July 2019

Citation: Becheva M, Petrova G, Kirkova A, Atanasov P (2019) Kinesitherapeutic behaviour in conservative treatment of coxarthrosis - case report. Pharmacia 66(2): 75-77. https://doi.org/10.3897/pharmacia.66.e36143

\begin{abstract}
Hip arthrosis is the main cause of disability of all degenerative joint diseases and therefore it is considered to be of social significance. The presented clinical case aims to confirm the efficacy of the applied kinesitherapeutic program in conservative treatment of 62 -year-old patient with right-sided coxarthrosis. The kinesitherapeutic methods included right lower limb massage, suspension therapy, tractions and manual movements of the right hip joint, positional treatment, active exercisesinan openkinetic chain, postisometric relaxation and stretching for shortened muscles. The pain symptoms were reduced, the volume of movement in the right hip increased, the strength of the right hip joint stabilizer muscles partially improved.
\end{abstract}

\section{Keywords}

coxarthrosis, functional deficiency, kinesitherapy

\section{Introduction}

Hip arthrosis is the main cause of disability in all degenerative joint diseases, therefore it is considered to be of social significance (Becheva 2015). The treatment and rehabilitation of such patients requires the use of serious medical and social activities (Krastev 2010, Kostov 2016). The application of manual kinesitherapeutic techniques is essential because it helps reduce pain symptoms and improve patients' quality of life of (Steenstrupa et al. 2012).

The aim of the presented clinical case is to confirm the efficacy of the applied kinesitherapeutic program in conservative treatment of a patient with right-sided coxarthrosis.

\section{Patient presentation}

We present a patient aged 62 years admitted for outpatient treatment with coxarthrosis of the right hip joint. "Gluteus medieus" type of gait and a visible limb shortening was found.

\section{Results}

We conducted the kinesitherapeutic procedure once a day. The exercise complex lasted 40-50 minutes. The average number of procedures within the treatment was 10 . 
We used manual muscle testing, angulation, centimetry at baseline and at the end of the rehabilitation course (Tables 1-3) to determine functional deficit and result objectivity.

Table 1. Manually muscular testing of motor muscles in hip joints.

\begin{tabular}{lcccc}
\hline Tested muscles & \multicolumn{2}{c}{ At baseline } & \multicolumn{2}{c}{ At end } \\
\cline { 2 - 5 } & $\begin{array}{c}\text { Right lower } \\
\text { limb }\end{array}$ & $\begin{array}{c}\text { Left lower } \\
\text { limb }\end{array}$ & $\begin{array}{c}\text { Right lower } \\
\text { limb }\end{array}$ & $\begin{array}{c}\text { Left lower } \\
\text { limb }\end{array}$ \\
\hline Hip flexors & 4 & 5 & 4 & 5 \\
Hip extensors & 3 & 4 & 4 & 4 \\
Hip abductors & 3 & 4 & 4 & 4 \\
Hip adductor & 4 & 5 & 4 & 5 \\
External hip rotators & 4 & 5 & 4 & 5 \\
Internal hip rotators & 3 & 4 & 4 & 4 \\
Analytical test for m. & 3 & 4 & 4 & 4 \\
gluteus maximus & & & & \\
m. quadriceps femoris & 3 & 4 & 4 & 4 \\
m. tibialis anterior & 3 & 4 & 4 & 4 \\
m. fibularislonqus and & 3 & 4 & 4 & 4 \\
m. fibularisbrevis & & & &
\end{tabular}

Table 2. Hip joint angulation.

\begin{tabular}{llll}
\hline \multicolumn{2}{c}{ At baseline } & \multicolumn{2}{c}{ At end } \\
\hline Right hip joint & \multicolumn{1}{c}{ Left hip joint } & \multicolumn{1}{c}{ Right hip joint } & \multicolumn{1}{c}{ Left hip joint } \\
\hline S: $8^{\circ}-0^{\circ}-70^{\circ}$ & S: $15^{\circ}-0^{\circ}-120^{\circ}$ & S: $15^{\circ}-0^{\circ}-82^{\circ}$ & S: $15^{\circ}-0^{\circ}-120^{\circ}$ \\
F: $15^{\circ}-0^{\circ}-10^{\circ}$ & F: $35^{\circ}-0^{\circ}-15^{\circ}$ & F: $29^{\circ}-0^{\circ}-15^{\circ}$ & F: $35^{\circ}-0^{\circ}-15^{\circ}$ \\
R: $35^{\circ}-0^{\circ}-18^{\circ}$ & R: $42^{\circ}-0^{\circ}-42^{\circ}$ & R: $40^{\circ}-0^{\circ}-25^{\circ}$ & R: $42^{\circ}-0^{\circ}-42^{\circ}$ \\
\hline
\end{tabular}

Table 3. Measurement of the circumference of the thigh and lower leg.

\begin{tabular}{lcccc}
\hline Circumferences & \multicolumn{2}{c}{ At baseline } & \multicolumn{2}{c}{ At end } \\
\cline { 2 - 5 } & $\begin{array}{c}\text { Right } \\
\text { lower limb }\end{array}$ & $\begin{array}{c}\text { Left lower } \\
\text { limb }\end{array}$ & $\begin{array}{c}\text { Right lower } \\
\text { limb }\end{array}$ & $\begin{array}{c}\text { Left lower } \\
\text { limb }\end{array}$ \\
\hline $\begin{array}{l}\text { Thigh } 5 \mathrm{~cm} \text { from } \\
\text { the top of patella }\end{array}$ & 45 & 46.5 & 45.5 & 46.5 \\
$\begin{array}{l}\text { Thigh } 8 \text { cm from } \\
\text { the top of patella }\end{array}$ & 47 & 48.5 & 47.5 & 48.5 \\
\begin{tabular}{l} 
Lower leg \\
\hline
\end{tabular} & 40 & 41 & 40.5 & 41.5 \\
\hline
\end{tabular}

We applied a test to elevate an object from the ground to examine the flexibility of hip joints.

"Elevating an object from the floor" - when the patient attempted to lift paper from the floor, she squatted on the sturdy leg, resting on it at an extended hip of the affected limb - assessment 3.

To evaluate the pain symptom, we applied a visual analogue pain scale. The patient reported a right hip pain in motion assessed at 6 on the VAS at the beginning of outpatient treatment. At the end of the period of the applied kinesitherapeutic program, the pain symptom was assessed at 3 .

The aim of the applied kinesitherapy was to improve the patient's functional condition.

Given the deficiency of the affected structures, the tasks we set ourselves were to reduce the pain, improve the volume of movement of the extension, abduction and internal rotation in the right hip, contracture prevention, muscle imbalance correction, trophic improvement, strength and accessory movements in the right hip, as well as improving the gait parameters.

Kinesitherapy started with a baseline massage, left lateral position with a pillow between the legs. We massaged around the large trochanter in order to improve trophics in the region, bearing in mind that there are to be found the extreme grip points of the pelvis stabilizers ( $\mathrm{m}$. gluteus medius, $\mathrm{m}$. gluteus minimus). We continued with a toning massage of $\mathrm{m}$. quadriceps femoris to improve its knee stabilization function during the walking phase. Kinesitherapy continued with a right hip suspension for five minutes at the frontal and sagittal plane. From a baseline supine position, we initially applied isometric contractions for gluteal muscles and for $\mathrm{m}$. quadriceps femoris, and active-assisted exercises for muscle extensions, abductors and internal rotators for right hip joint. We were advancing with isotonic exercises for right lower limb in an open kinetic chain. Analytically we practiced m. gluteus maximus, antigravitationally, and at the end of the procedures, we applied manually moderate resistance. We worked the three glutei (gluteus medius, gluteus maximus, gluteus minimus) from a left lateral position baseline with verbal instructions, the patient performing abduction, extension and internal rotation in the right hip joint. We trained the sub-umbilical abdominal muscles in the isotonic mode from supine position and applied a post-symmetric relaxation of $\mathrm{m}$. quadratus lumborum, $\mathrm{m}$. rectus femoris, m. iliopsoas, in order to overcome low cross syndrome. We trained the patient in pelvic re-inclinatory exercises.

To correct the muscle imbalance, we applied a postisometric relaxation of $\mathrm{m}$. piriformis and the adductors of the right hip joint. Due to the shortening of $m$. triceps surae, we had to apply a stretch of $\mathrm{mm}$. gastrocnemius and $\mathrm{m}$. soleus.

We trained analytically $m$. quadriceps femoris, m. tibialis anterior, $\mathrm{m}$. fibularis lonqus and $\mathrm{m}$. fibularis brevis in isotonic mode in an open kinetic chain. We applied traction along the femoral neck and along the femoral axis; we performed caudal and dorsal gliding to improve the articular joint movements. We trained the patient to walk with a cane she wore on the strong side and carried it out with her sick leg. The climbing of the stairs was done by first putting the cane then the healthy leg and finally the sick one. On descending, she first put the cane, then the sick leg, and finally the healthy leg.

We applied isotonic and eccentric exercise for all muscle groups for the healthy lower limb, whose good support function was of great importance for walking safety.

As a result of the applied kinesitherapy at the end of the procedures, the muscular strength of the extensors, abductors and internal rotators of the right hip joint increased leading to the three movements being performed against moderate resistance. Kinesitherapy helped increase muscle mass on the right thigh and lower leg by $0.5 \mathrm{~mm}$, but the difference between the two hips and legs remained within $1 \mathrm{~cm}$. The application of a kinesitherapeutic program made it possible to partially increase the volume of movement of the extension, abduction and internal rotation in the right hip, which we attribute to the insufficient number of procedures. The shortening of the limb remained permanently $1.5 \mathrm{~cm}$. We advised the patient to compensate for the length of the right lower limb by putting a slip-sole on the right shoe.

We gave advice to the patient not to burden the hip joint in sitting and in upright position. We also recommended taking a face down position to prevent flexion contractility in the hip joint. 


\section{Discussion}

Muscular weakness and imbalance in the hip joint result in distortion of the lumbo-pelvic mechanism and abnormal arthrokinematics in the hip joint, which is a prerequisite for pain syndromes in the lumbar spine, sacroiliac joints or hip joints (Popov 2009).

The applied profound massage, increased the hyperemia and trophicity of the treated structures, which helped with the elimination of metabolic products (Dufur et al. 1999). The reduction of pain and improvement of joint trophics is attributed to the massage techniques and to the tractions performed in the right hip (Estrade 2008). Manual mobilization also causes a refractive reduction of regional nociception (Krastev 2016). Improving the volume of movement of the extension, abduction and internal rotation in the right hip joint is attributed to applied manual-mobilization techniques aimed at normalizing joint play. We applied caudal sliding to increase flexion and inner rotation in the right hip, ventral sliding to increase right hip extension, considering that manual mobilization restores the volume of movements, helps the joint cartilage trophics, improves the metabolism of soft tissue structures, and the speed and quality of link regeneration (Popov et al. 2013).

The restoration of motor control we attributed to exercising of consecutive isometric contractions and rhythmic stabilization that stimulate the holding and adaptation of the posture to the applied external forces from a starting position on a large therapeutic ball. Enhanced steady-state control contributed to greater security in day-to-day activities.

\section{References}

Becheva M (2015) Kinesitherapy in diseases of the locomotive system. MU , Plovdiv, 60-63 pp.

Bergeron Y, Fortin L, Leclaire R (2008) Pathologie médicale de l'appareillocomoteur ( $2^{\text {nd }}$ edn). Saint-Hyacinthe, Edisem/Maloine.

Dufur M, Colne P, Gouilly P, Chemoul G (1999) Massage et massotherapieEffet, technique et applicaton. Maloine: 223-233.

Estrade JL (2008) Les tractions de hanchesontd'autant plus bénéfiquessur le coxarthrosesqu'ellessontintenses. Kinésithérapie, la revue 8(74): 16. https://doi.org/10.1016/S1779-0123(08)70028-7

Kostov R, Yordanov K (2010) Application of Rhythmic Stabilization in a Closed Kinetic Chain, in Restoring Dynamic Hip Stabilization. Student Scientific Conference, Rousse.

Krastev T (2016) Kinesitherapy in functional disorders of the sacroiliac joint. PhD Thesis, Summary, Blagoevgrad, $26 \mathrm{pp}$.

Pierron G, Leroy A, Peninou G, Dufour M, Genot C (2000) Kinésithérapie 2 Member inferieur. Bilan techniques passives et actives. Science. Flamarion medicine 107-287.

Popov N (2009) Kinesiology and pathogenesis of the locomotive system. Press Sofia, Sofia, 247-276.

Popov N, Popova D, Grueva T (2013) Physiotherapy in muscular skeletal dysfunctions of the lower limbs. NSA-Press, Sofia, 94-113.

Rannou F, Poiraudeau S (2010) Nonpharmacological approaches for the treatment of osteoarthritis. Best Practice \& Research: Clinical Rheumatology 24(1): 93-106. https://doi.org/10.1016/j.berh.2009.08.013
(Pierron et al. 2000). Our goal was to improve joint stability, strengthening muscles pelvic stabilizers. As a result of sequential isotonic contractions and rhythmic stabilization applied to the pelvic stabilizers, the right hip joint load was reduced. (Kostov and Yordanov 2010). Improving muscle strength and proprioception using exercise programs can reduce the development of coxarthrosis (Bergeron et al. 2008).

The purpose of muscle stretching was to improve and increase articular amplitudes of movement (Sanchez et al. 2010).

Applying treatment from a facial position improved the extensions in the right hip and prevented deepening of the flexion contracture in the joint. Experts believe that administering treatment from a position may stop the progression of coxarthrosis and postpone hip joint endoprostheses (Rannou and Poiraudeau 2010).

According to the clinical experience, we recommended the patient to wear pads to reduce the pressure but also to help align lower leg length pads and shoes (Zhang et al. 2005). While adhering to OARSI's recommendations (Zhang et al. 2008), we used for our exercises a tool - a walking stick.

\section{Conclusion}

As a result of the applied kinesitherapeutic method, we observed a reduction in pain symptoms, an increase in the right hip joint movement, and an improvement in the muscle strength of the extensors and right hip stabilizers. The shortening of the limb remained permanently $1.5 \mathrm{~cm}$.

Sanchez K, Eloumri A,Rannou F, Poiraudeau S (2010)Prises en charge non pharmacologists and non-surgical artists: orthèses, exercices. Non-pharmacological and nons urgent therapies for osteoarthritis: Orthosis, exercises. La Presse médicale 39(11): 1172-1179. https:// doi.org/10.1016/j.lpm.2009.11.022

Steenstrupa B, Roudeslib M, Beaufils J (2012) Évaluation of a protocol for the treatment of ambulatory kinesiotherapy in coxarthrose. Kinésithérapie, Revue 12(127): 67-77. https://doi.org/10.1016/j.kine.2012.02.002

Zhang W, Doherty M, Arden N, Bannwarth B, Bijlsma J, Gunther K-P, Hauselmann HJ, Herrero-Beaumont G, Jordan K, Kaklamanis P, Leeb B, Lequesne M, Lohmander S, Mazieres B, Martin-Mola E, Pavelka K, Pendleton A, Punzi L, Swoboda B, Varatojo R, Verbruggen G, Zimmermann-Gorska I, Dougados M (2005)EULAR evidence based recommendations for the management of hip osteoarthritis: report of a task force of the EULAR Standing Committee for International Clinical Studies Including Therapeutics (ESCISIT). Ann Rheum Dis 64: 669-681. https://doi.org/10.1136/ard.2004.028886

Zhang W, Moskowitz RW, Nuki G, Abramson S, Altman RD, Arden N, Bierma-Zeinstra S, Brandt KD, Croft P, Doherty M, Dougados M, Hochberg M, Hunter DJ, Kwoh K, Lohmander LS, Tugwell P (2008) OARSI recommendations for the management of osteoarthritis and knee osteoarthritis, Part II: OARSI evidence-based, expert consensus guide-lines. Osteoarthritis Cartilage 16(2): 137-162. https://doi. org/10.1016/j.joca.2007.12.013 